\title{
Desenvolvimento das estratégias de leitura em dois diferentes métodos de alfabetização
}

\author{
Dvelopment of reading strategies in two different methods of literacy
}

\author{
Dalva Maria Alves Godoy \\ Universidade do Estado de Santa Catarina - UDESC - Santa Catarina- Brasil \\ Ângela Maria Vieira Pinheiro \\ Universidade Federal de Minas Gerais - UFMG - Minas Gerais - Brasil
}

\begin{abstract}
Resumo: O presente estudo investiga o desenvolvimento da leitura no português brasileiro em fases bem iniciais de aprendizagem. Foram contrastados dois grupos de alunos, um em processo de alfabetização pelo método fônico $(\mathrm{N}=23)$ e outro pelo método global $(\mathrm{N}=19)$, ambos cursando o $2^{\circ}$ ano da rede particular de ensino $\left(M_{\text {idade }}=7 a\right.$ e $\left.9 \mathrm{~m}\right)$. Objetivou averiguar a influência do método de ensino no desenvolvimento das rotas fonológica e lexical. A leitura em voz alta foi avaliada por meio de uma lista de palavras manipuladas conforme a regularidade (regularirregular), frequência (alta-baixa), extensão (curta-longa) e lexicalidade (palavrapseudopalavra). Os resultados confirmam que a leitura no português, mesmo em fase inicial de aprendizagem, é processada pela rota fonológica e lexical de forma concomitante. A interação entre as variáveis psicolinguísticas e o método de ensino mostrou que o desenvolvimento da rota lexical é favorecido pelo método fônico.
\end{abstract}

Palavras-chave: Processamento da leitura. Rota fonológica. Rota lexical. Método de ensino.

Abstract: The present study investigates the development of reading in Brazilian Portuguese in very early stages of learning. There were analyzed two groups of students, one in the literacy process by the phonic method $(\mathrm{N}=23)$ and the other by the global method $(\mathrm{N}=19)$, both attending the second year of the private school system ( $\mathrm{M}_{\mathrm{age}}=7 ; 9$ years). The objective was to investigate the influence of the teaching method on the development of phonological and lexical routes. Reading aloud was evaluated through a list of words manipulated according to regularity (regular-irregular), frequency (high-low), extension (short-long) and lexicality (wordpseudoword). The results confirm that the reading in Portuguese, even in the initial phase of learning, is processed by the phonological and lexical route concomitantly. The interaction between the psycholinguistic variables and the teaching method showed that the development of the lexical route is favored by the phonic method.

Keywords: Reading processing. Phonological route. Lexical route. Teaching method. 


\section{Introdução}

Segundo os modelos de leitura derivados da teoria de dupla rota (COLTHEART et al. 2001), o processamento da leitura em leitores habilidosos é, realizado através do processo lexical - que confere velocidade e eficiência à leitura e, pelo processo fonológico, quando se trata de palavras pouco familiares ou nunca lidas. Classicamente a avaliação desse processamento utiliza a manipulação de variáveis psicolinguísticas das palavras (lexicalidade, frequência, regularidade e extensão) para colocar em evidência um, ou outro, processo. Em princípio as palavras irregulares só podem ser lidas corretamente pela via lexical, enquanto as pseudopalavras, por não terem sua representação fonológica e ortográfica armazenada no léxico mental, devem ser lidas obrigatoriamente pela via fonológica. A presença do efeito de frequência e de lexicalidade, na ausência do efeito de regularidade, demonstra o funcionamento da via lexical, enquanto a do efeito de regularidade, na ausência do efeito de frequência ou de lexicalidade, indica o processamento da leitura pela via fonológica.

Estudos em diferentes ortografias têm procurado colocar em evidência a universalidade desses processos ao passo que têm também questionado se o desenvolvimento de um ou de outro processo no curso da escolarização pode ser influenciado pelo tipo de ortografia que se aprende ou mesmo pelo método de ensino (PINHEIRO, 1995; LANDERL, 2000; DEFIOR, MARTOS; CARY, 2002; ARO; WIMMER, 2003; SPRENGER-CHAROLLES et al., 2003; ZOCCOLOTTI et al., 2009).

O desenvolvimento prioritário de um ou outro processo durante as fases iniciais de aprendizagem da leitura,parece depender das características de cada ortografia. Para Sprenger-Charoles et al. (2003), se o processamento fonológico desempenha papel indispensável para a aprendizagem da leitura, conforme afirma Share (1995), o grau de consistência de uma ortografia deve determinar esta aprendizagem. Desse modo, nas ortografias transparentes, como o processo fonológico se instala como o mais confiável para alcançar a pronúncia correta das palavras, a dependência desse processo seria maior do que nas ortografias opacas.

No caso das ortografias transparentes o leitor iniciante pode, baseando-se nas correspondências grafema-fonema, ler com precisão um número considerável de palavras presentes em seu cotidiano. Ao enfocar as correspondências grafema-fonema o aprendiz desenvolve a rota lexical baseada em unidades sub-lexicais. Este exercício eficiente da rota fonológica, na visão de Share (1995), é condição sine qua non para a aprendizagem da leitura, pois é através desse mecanismo que as representações ortográficas das palavras vão sendo armazenadas no léxico mental para serem posteriormente recuperadas e, assim, imprimir velocidade à leitura.

O desenvolvimento preferencial por uma das rotas de processamento da leitura também é influenciado pelo método de ensino. Wimmer e Goswami (1994) demonstraram, ao compararem a aprendizagem da leitura em duas diferentes ortografias, inglesa e alemã, que as crianças germânicas, ao serem ensinadas pelo método fônico, eram encorajadas desde o início da aprendizagem a adotar o processamento fonológico, o que se constituiu em um ganho, em relação às crianças inglesas, para a leitura de palavras novas. Essas crianças, segundo os autores, à medida que possuíam a rota fonológica bem desenvolvida, podiam também ler muito melhor as pseudopalavras e utilizavam a rota lexical para a leitura de palavras de alta frequência. Ao utilizar melhor o processamento fonológico para ler palavras novas, o léxico ortográfico foi expandido e isso se constituiu em uma vantagem para utilizar a via lexical para ler palavras de alta frequência. Entretanto, é necessário lembrar que nesse estudo há interferência paralela das características de cada ortografia, o inglês encontra-se na extremidade de opacidade, enquanto o alemão é considerado transparente. Desse modo, a eficiência da rota fonológica pode ter sido estimulada pelas correspondências consistentes da ortografia do alemão.

Leybaert e Content (1995) investigaram a influência do método em crianças francesas de $2^{\underline{a}}, 4^{a}$ 
e 6ª série que foram alfabetizadas pelo método fônico e global. A hipótese dos autores era a de que se o método influenciasse a aprendizagem da leitura, as crianças expostas ao método fônico deveriam desenvolver, prioritariamente, a capacidade de decodificação (rota fonológica) e, em contrapartida, as crianças do método global deveriam desenvolver, prioritariamente, a competência do reconhecimento direto das palavras (rota lexical). A hipótese não foi confirmada: o método de ensino não determinava o uso prioritário de uma ou outra estratégia de leitura. Os resultados mostraram ainda que as crianças de $2^{a}$ série do método global não utilizavam da estratégia lexical, e, além disso, de forma paradoxal, a rota lexical, nessas crianças parecia menos desenvolvida do que nas crianças ensinadas através do método fônico.

Os estudos comparativos entre ortografias têm suscitado várias questões. No estudo de Defior et al. (2002) foi comparada a aprendizagem da leitura de alunos de $1^{\underline{a}}$ a $4^{\underline{a}}$ série em duas ortografias consideradas transparentes: o espanhol e o português europeu. Embora as diferenças no grau de consistência entre essas duas ortografias fossem pequenas, os resultados apontaram diferenças significativas: as crianças espanholas liam as pseudopalavras muito mais rápido do que as portuguesas, e o ritmo fluente de leitura era alcançado por volta da $2^{\mathrm{a}}$ série, ao passo que as portuguesas alcançavam fluência apenas na 3á série. $\mathrm{Na}$ análise do padrão de erros de leitura constatou-se que as crianças espanholas pareciam não utilizar o processo lexical desde o início, enquanto as portuguesas utilizavam ambos os processos. Segundo os autores é provável que as crianças espanholas não utilizassem o processo lexical em função da maior consistência do espanhol em relação ao português. Nesse caso, a consistência da ortografia levaria à preferência pelo processo fonológico.

Diante desses resultados estima-se que entre as ortografias do português brasileiro e europeu haja pequenas diferenças quanto ao desenvolvimento das estratégias de processamento de leitura. Não se tem notícias de estudos comparativos entre essas duas ortografias até o momento, bem como de estudos empíricos em que o português brasileiro tenha sido comparado a outras ortografias. Como parâmetro podemos nos apoiar nos resultados de Sucena e Castro (2005) que avaliou a leitura de palavras e pseudopalavras, classificadas segundo diferentes graus de consistência, em estudantes de $1^{\underline{a}}$ a $4^{\underline{a}}$ série. As autoras encontraram que as crianças portuguesas utilizavam concomitantemente 0 processo fonológico e lexical nessas fases iniciais, apontando para um desenvolvimento em paralelo das duas rotas, confirmando os resultados de Defior et al., 2002.

Em relação ao português brasileiro, o estudo pioneiro de Pinheiro (1995) com crianças brasileiras de $1^{\text {a }}$ a $4^{\text {a }}$ série ${ }^{1}$ comprovou a legitimidade do modelo de duplo processamento para a nossa ortografia. Nesse estudo foram demonstrados os efeitos de frequência e lexicalidade em todas as séries escolares, tanto em termos de tempo de processamento, como em termos de precisão. $O$ efeito de extensão foi observado de maneira mais significativa apenas nas séries iniciais, assim como o efeito de regularidade. $\mathrm{O}$ uso do processo fonológico se restringiu às séries iniciais ao passo que 0 processo lexical se desenvolveu em conjunto, desde a 1a série. A análise de correlação entre palavras e pseudopalavras demonstrou 0 desenvolvimento simultâneo das duas vias de processamento, ao longo de todas as séries estudadas. Já na $1^{\text {a }}$ série as crianças utilizavam, preferencialmente, a rota fonológica para a leitura, mas houve, concomitantemente, influência da rota lexical, marcada pelo efeito de frequência. À medida que avançaram as séries escolares, houve uma transição no predomínio do uso da rota fonológica para o uso da rota lexical, que ocorreu por volta da $3^{\underline{a}}$ série escolar.

No estudo de Pinheiro, de forma semelhante ao de Sucena e Castro (2005), as duas rotas de processamento da leitura foram utilizadas desde o

\footnotetext{
1 Atualmente, com o ensino fundamental de 9 anos, a $1^{\text {a }}$ série equivaleria ao $2^{\circ}$ ano, a $2^{\underline{a}}$ série ao $3^{\circ}$ ano, a $3^{\text {a }}$ série ao $4^{\circ}$ ano e a $4^{\text {a }}$ série ao $5^{\circ}$ ano.
} 
início, marcando assim, apesar do reconhecido grau de transparência do português brasileiro, o desenvolvimento da rota lexical e não a dependência do processo fonológico.

No estudo de Salles e Parente (2007) o foco da investigação foi dado à precisão do processamento fonológico e lexical em crianças brasileiras que cursavam a $2^{\mathrm{a}}$ série $^{2}$. Os resultados indicaram um predomínio do processo fonológico, atestado pelo melhor desempenho em pseudopalavras comparado à leitura de palavras e pelos efeitos de regularidade e extensão, nas séries iniciais. Entretanto, da mesma forma que os resultados de Pinheiro (1995), foi confirmado o uso concomitante dos dois processos para a leitura.

Salles e Parente (2002) realizaram um interessante estudo com 76 alunos de $2^{\underline{a}}$ e $3^{\underline{a}}$ série $^{3}$ que frequentavam uma escola particular, que adotava a abordagem construtivista de ensino. A amostra foi classificada em quatro tipos de leitores: "bons leitores" - que utilizam ambos os processos para leitura, "leitores que utilizam preferencialmente a rota lexical", "leitores que utilizam preferencialmente a rota fonológica" e "maus leitores" - fracos em ambos os processos. Esse agrupamento foi pautado nos resultados da avaliação da leitura de uma lista de palavras e de pseudopalavras que variaram em termos de extensão, regularidade e frequência. Desse modo pôde-se observar que na $2^{\mathrm{a}}$ série, $37,5 \%$ dos alunos foram caracterizados como "leitores que utilizavam preferencialmente a rota fonológica" e $30 \%$, como "bons leitores" que utilizavam ambas as rotas. $\mathrm{Na} 3^{\mathrm{a}}$ série, $69,4 \%$ dos estudantes foram caracterizados como "bons leitores" e apenas 5,6\% como "leitores que utilizavam preferencialmente a rota fonológica". Nessa fase de escolarização (antiga $2^{\underline{a}}$ série, atual $3^{\circ}$ ano), portanto, embora haja predomínio da rota fonológica para leitura, a rota lexical está se desenvolvendo em boa parte dos estudantes. Vale ressaltar, entretanto, que o estudo teve caráter transversal, ou seja, a diferença observada nos

\footnotetext{
${ }^{2} \mathrm{~A} 2^{\mathrm{a}}$ série na época do estudo corresponde ao $3^{\circ}$ ano atual.

${ }^{3}$ Equivalentes ao $3^{\circ}$ e $4^{\circ}$ ano atual.
}

desempenhos entre $2^{\mathrm{a}}$ e $3^{\mathrm{a}}$ série resultou de uma única observação.

Os resultados obtidos em relação ao desenvolvimento das rotas fonológica e lexical para o português brasileiro nas fases iniciais de escolarização indicam que a rota fonológica é utilizada como preferencial apenas nos estágios iniciais de aprendizagem, mas os dois processos se desenvolvem em paralelo desde o início e a rota lexical predomina a partir do $4^{\circ}$ ano. Parece haver ainda imprecisão em relação aos achados quanto ao desenvolvimento da rota fonológica, se ela perdura como preferencial nas séries mais avançadas, $4^{\circ}$ e $5^{\circ}$ ano, ou se prevalece apenas no início, $2^{\circ}$ e $3^{\circ}$ ano.

Lembrando a equação de Gough e Tunmer (1986) em que a leitura é o produto da decodificação e da compreensão, os resultados até aqui auferidos nos revelam que o processo de decodificação parece ser estabelecido até $03^{\circ}$ ano (antiga $2^{\underline{a}}$ série), quando os estudantes estão se apropriando e sistematizando os conhecimentos sobre o sistema alfabético do português brasileiro. A partir do $3^{\circ}$ ano é possível que a leitura ganhe fluência com o funcionamento mais eficiente do processo lexical e, a essa altura, os processos de compreensão possam ser o maior objetivo de ensino.

No presente artigo, ao investigar o processamento de leitura em estudantes de $2^{0}$ ano (antiga $1^{\text {a }}$ série) espera-se ampliar os resultados com relação ao desenvolvimento das rotas de processamento para o português brasileiro em uma fase bem inicial da aprendizagem (à exceção do trabalho de Pinheiro (1995), não foram encontradas pesquisas com esse nível de escolarização). Ao mesmo tempo, este artigo objetiva explorar o efeito do método de alfabetização sobre o desenvolvimento desse processamento.

Lúcio e Pinheiro (2011) desenharam um panorama sobre os 20 anos da pesquisa brasileira com relação à avaliação da leitura de palavras. Um dos pontos levantados pelas autoras foi em relação à classificação das palavras quanto à regularidade. $\mathrm{O}$ efeito de regularidade pode ser obtido, ou não, em função da direção da classificação das palavras - 
direção grafema-fonema (leitura) ou fonema-grafema (escrita), o que ainda merece aprofundamento por parte dos pesquisadores.

O efeito de regularidade é especialmente difícil de ser avaliado em uma ortografia transparente, pois em função da consistência das regras ortográficas as palavras podem ser comumente lidas pela rota fonológica e a rapidez e a eficiência do processamento poderiam ser marcadas pela eficiência do leitor em aplicar tais regras. Além disso, dentro do universo de palavras categorizadas em termos de frequência e de extensão, o número de palavras que contêm irregularidades para a leitura, como as de ocorrência do grafema " $x$ " em posição intervocálica, é muito pequeno, principalmente se considerado o léxico de crianças em fase inicial de alfabetização. Dessa forma Pinheiro (2003) desenvolveu uma lista para a avaliação da leitura de crianças de $1^{\underline{a}}$ e $2^{\underline{a}}$ série (atual $2^{\circ}$ e $3^{\circ}$ ano) em que a irregularidade é avaliada principalmente por meio de palavras em que a ambiguidade da pronúncia das vogais "e" e "o" pode ser eliciada.

Neste estudo a lista de palavras de Pinheiro (2003) foi utilizada para investigar o processamento da leitura em uma fase bem inicial de aprendizagem ( $2^{\circ}$ ano) quando as crianças recebiam duas diferentes abordagens de ensino. Objetiva-se com isso compreender como se comportam as rotas fonológica e lexical em função das características da ortografia do português brasileiro e do método de alfabetização.

\section{MÉTODO}

Esta pesquisa é parte de um estudo longitudinal que investigou a influência do método de ensino sobre o desenvolvimento das habilidades de consciência fonológica, da leitura e da escrita. Os principais resultados encontram-se publicados em Godoy, Pinheiro e Defior (2017). Os dados analisados neste artigo referem-se à leitura de palavras e pseudopalavras, quando as crianças estavam no $2^{\circ}$ ano letivo.

\section{PARTICIPANTES}

Participaram deste estudo um total de 41 alunos do $2^{\circ}$ ano da Educação Básica da rede particular de ensino com idade média de 7 anos e 9 meses. Todos os cuidados éticos em relação à pesquisa foram tomados, os participantes receberam previamente a autorização de seus pais ou responsáveis. Um grupo $(\mathrm{N}=23)$ pertencia a uma instituição escolar em que o ensino da leitura se pautava na instrução sistemática das correspondências entre grafemas e fonemas (Método Fônico). O outro grupo ( $\mathrm{N}=19)$ recebia instrução de leitura que privilegiava o uso do contexto e não havia ensino explícito das relações grafema-fonema em uma abordagem construtivista (Método Global). Os alunos foram avaliados próximo ao final do ano letivo (outubro).

\section{INSTRUMENTOS DE AVALIAÇÃO}

Foram utilizadas duas provas de leitura em voz alta.

Leitura de palavras: 72 palavras experimentais de Pinheiro (2003) classificadas em termos de frequência (alta - baixa), regularidade (regular e irregular) e extensão (curtas - de 4 e 5 letras e longas - de 6 e 7 letras).

Leitura de pseudopalavras: 72 itens gerados a partir da lista de palavras, substituindo-se, em cada uma das palavras, um ou dois grafemas consonantais, na maioria das vezes, de forma a obter uma pseudopalavra. Estas foram classificadas em itens curtos, de 4 e 5 letras (40 itens), ou longos, de 6 e 7 letras (32 itens).

\section{PROCEDIMENTOS}

De coleta de dados

Em ambas as provas, os itens foram apresentados um de cada vez na tela do computador, por meio do software Cognitive Workshop, de forma aleatória. Seis itens de treino precederam a execução da prova que foi aplicada individualmente. A criança era solicitada a ler a palavra tão rápida e corretamente quanto possível. O critério de correção considerou como resposta correta apenas as emissões feitas sem hesitação, silabação ou 
autocorreção. O escore máximo foi de 72 pontos, em cada uma das provas. Os desempenhos foram analisados em termos de medidas de tempo de reação $(R T)$ para as respostas corretas, em milésimos de segundos, e porcentagem de respostas corretas (RC).

DE ANÁLISE DOS DADOS

A análise do processamento da leitura foi realizada comparando a porcentagem média de respostas corretas $(R C)$ e a média de tempo de reação $(R T)$, para as respostas corretas, de cada sujeito através de ANOVA de medidas repetidas em que os fatores dentro do grupo foram: lexicalidade (palavra x pseudopalavra), extensão (itens curtos $x$ itens longos), regularidade (palavras regulares $x$ irregulares) e frequência (alta $x$ baixa), e o fator entregrupos, o método de ensino: global $x$ fônico. Os efeitos principais foram comparados através do modelo de ajuste de Bonferroni. Foi empregado o pacote estatístico SPSS para as análises.

\section{RESULTADOS}

Os desempenhos médios em leitura para cada grupo, método fônico e método global, para cada uma das categorias de palavras e pseudopalavras estão expressos na Tabela 1.

\section{TABELA 1}

Porcentagem média de respostas corretas e desvio padrão (dp) para a leitura de diferentes categorias de palavras, e pseudopalavras, por método

\begin{tabular}{|c|c|c|c|c|}
\hline & \multicolumn{2}{|c|}{$\begin{array}{c}\text { MÉTODO GLOBAL } \\
\text { N=18 }\end{array}$} & \multicolumn{2}{|c|}{$\begin{array}{l}\text { MÉTODO FÔNIœ } \\
\qquad N=23\end{array}$} \\
\hline & Média & dp & Média & $d p$ \\
\hline PAL & 66,67 & $(21,21)$ & 76,63 & $(18,06)$ \\
\hline PAL-AF & 78,39 & $(20,58)$ & 88,04 & $(17,89)$ \\
\hline PAL-BF & 54,94 & $(23,08)$ & 65,22 & $(19,91)$ \\
\hline PAL-CURTA & 68,89 & $(19,65)$ & 78,37 & $(16,83)$ \\
\hline PAL-LONGA & 63,89 & $(24,59)$ & 74,46 & $(20,44)$ \\
\hline PSD & 59,49 & $(20,15)$ & 68,78 & $(22,89)$ \\
\hline PSD-CURTA & 67,92 & $(19,50)$ & 72,83 & $(23,32)$ \\
\hline PSD-LONGA & 48,96 & $(22,64)$ & 63,73 & $(22,88)$ \\
\hline RE-AF-curta & 85,00 & $(16,18)$ & 93,04 & $(13,29)$ \\
\hline RE-AF-longa & 80,56 & $(25,80)$ & 86,96 & $(22,76)$ \\
\hline RE-BF-curta & 63,33 & $(23,01)$ & 76,52 & $(21,66)$ \\
\hline RE-BF-longa & 60,42 & $(27,87)$ & 74,46 & $(26,51)$ \\
\hline IRR-AF-curta & 79,44 & $(24,85)$ & 83,91 & $(21,69)$ \\
\hline IRR-AF-longa & 66,67 & $(27,79)$ & 88,04 & $(21,81)$ \\
\hline IRR-BF-curta & 47,78 & $(22,90)$ & 60,00 & $(21,11)$ \\
\hline IRR-BF-longa & 47,92 & $(28,52)$ & 48,37 & $(23,63)$ \\
\hline
\end{tabular}

Com o objetivo de sintetizar os resultados e dirigir o foco deste artigo, serão reportados apenas os resultados significativos em termos dos efeitos principais e das interações de terceira ${ }^{4}$ e quarta ordem, neste caso, quando houver interação com a variável método.

Primeiramente, quatro efeitos principais foram estudados dentro do grupo: lexicalidade, extensão regularidade e frequência, conjugados ao efeito método, fator entre grupos. $O$ efeito de lexicalidade $\mathrm{e}$ frequência indica o processamento pela via lexical, assim como, o efeito de extensão e regularidade, 0 processamento pela via fonológica. $\mathrm{O}$ efeito método

\footnotetext{
${ }^{4}$ Os efeitos de terceira ordem referem-se à interação entre três fatores e o efeito de quarta ordem, à interação entre quatro fatores.
} 
indica que os dois grupos, global e fônico, diferem em relação ao nível de desempenho em leitura.

Com relação à leitura de palavras as análises dos efeitos principais mostraram efeito de frequência, tanto para $\mathrm{RC}(F(1,39)=166,776 ; p<.001)$ como para RT $(F(1,35)=20,359 ; p<.001)$; efeito de extensão, para $\mathrm{RC}(F(1,39)=8,266 ; p<.01)$ e para RT $(F(1,35)=9,602 ; p<.01)$; efeito de regularidade para $\mathrm{RC}(F(1,39)=90,190 ; p<.001)$, mas não para $\mathrm{RT}$. Apenas quando foram eliminados os valores extremos $^{5}$ foi observado o efeito de regularidade com relação à velocidade de processamento $(F(1,31)=$ $4,473 ; p<.05)$, indicando que as palavras regulares foram lidas mais rapidamente que as irregulares. Não houve efeito Método, tanto para RC como para RT

Para avaliar o efeito de lexicalidade foram comparados os desempenhos entre palavras de altafrequência $(A F)$ e pseudopalavras, por um lado, e palavras de baixa frequência (BF) e pseudopalavras, por outro. A ANOVA mostrou um efeito principal de lexicalidade tanto em termos de precisão $(F(1,39)=$ $93,151 ; p<.001)$ como em termos de velocidade de processamento $(F(1,39)=13,897 ; p<.01)$ quando as palavras eram de AF. Para as palavras de BF o efeito foi marginalmente significativo em termos de precisão $(F(1,39)=3,618 ; p=.065)$, indicando que as pseudopalavras tendem a ser lidas com maior precisão do que as palavras de BF. Não foi observado efeito de lexicalidade em termos de velocidade de processamento ( $p>.05)$.

Não houve um efeito principal de método, tanto em termos de precisão $(F<1$.) como em termos de velocidade de processamento $(F<1$.), demonstrando que os dois grupos não diferem, significativamente, com relação ao nível de desempenho em leitura.

A análise de correlação entre os desempenhos em leitura de palavras e de pseudopalavras mostrou que, em termos de respostas corretas e velocidade de processamento, há uma forte correlação entre esses desempenhos $(r=0,847 ; p<.01$, para

\footnotetext{
5 Valores extremos se referem às médias encontradas acima, ou abaixo, de dois desvio padrão. Essa conduta estatística se justifica para tornar a mostra mais homogênea, possibilitando assim uma análise mais precisa. Tal conduta foi utilizada apenas com relação ao efeito de regularidade para velocidade de processamento. Para os outros resultados não houve necessidade de tal procedimento.
}

respostas corretas, e $r=0,792 ; p<.01$, para velocidade de processamento). Esse resultado indica que as crianças que leem mais rápida e precisamente as palavras também leem mais rápida e precisamente as pseudopalavras, demostrando que o processo lexical se desenvolve concomitantemente ao processo fonológico. Esse primeiro conjunto de resultados indica que o processamento da leitura ao final do $2^{\circ}$ ano está sendo feito tanto pela via lexical, como pela via fonológica, por ambos os grupos.

Passamos agora a apresentar as análises das interações entre as variáveis estudadas. A análise das interações é particularmente interessante uma vez que pode indicar se há diferenças entre os níveis de desempenho de uma variável em relação a cada uma das demais variáveis. É através dessa análise mais esmerada que as diferenças específicas em termos de estratégias, ou rotas, de processamento podem ser demonstradas de forma a identificar se os dois grupos estudados diferem quanto ao processamento de leitura. Como mencionado, apenas as interações de terceira e quarta ordem, significativas, e que envolvam a variável método, serão relatadas. Entretanto, sempre que necessário serão notificados resultados de interações de segunda ou terceira ordem para auxiliar na compreensão das análises. Das interações de terceira ordem, duas não foram significativas tanto para RC como RT: regularidade-frequência-extensão e regularidade-extensão-método.

Houve interação significativa entre lexicalidade, extensão e método, em termos de $\mathrm{RC}(F(1,39)=$ $6,111 ; p<.05)$, mas não em termos de $\mathrm{RT}(\mathrm{F}<.01)$. Observa-se que, enquanto o grupo de método fônico lê as palavras curtas melhor do que as pseudopalavras curtas, o grupo de método global lê as palavras e as pseudopalavras curtas no mesmo nível (Figura 1). Esse resultado indica que o grupo de método fônico parece utilizar o processo lexical para a leitura das palavras curtas de forma mais eficiente do que o grupo de método global, ou, que o grupo de método global pode estar utilizando o processo fonológico para o processamento dessas palavras (as interações de segunda ordem entre lexicalidade- 
extensão e extensão-método foram significativas apenas para $\mathrm{RC}$, enquanto a interação entre lexicalidade-método, não foi significativa para $\mathrm{RC}$ e $\mathrm{RT}$ ). Nota-se que o grupo de método fônico lê com maior precisão as palavras e pseudopalavras, curtas e longas do que o grupo de método global, o que parece indicar que o grupo de método fônico utiliza, com mais eficiência a via lexical e a via fonológica, do que o grupo de método global. Pelos resultados aportados parece haver uma superioridade, em termos de precisão, nos desempenhos do grupo de método fônico com relação à leitura de palavras e pseudopalavras. O grupo de método fônico tende a apresentar um léxico ortográfico um pouco mais desenvolvido e um domínio mais competente das regras de correspondência grafofonológica.

\section{FIGURA 1}

Interação entre lexicalidade, extensão e método, em termos de precisão, para leitura

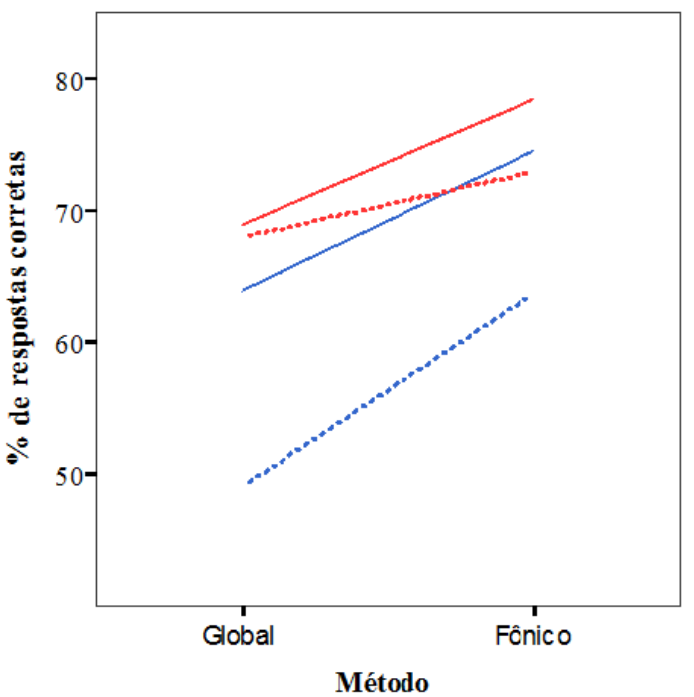

EXT

$\square$ curtas

longas

\section{LEX}

palav ra pseudopalavra

Houve interação entre regularidade, frequência e método em termos de porcentagem de respostas corretas $(F(1,39)=6,220 ; p<.05)$, mas não em termos de velocidade de processamento $(F<1$.). As interações de segunda ordem entre regularidademétodo e frequência-método, não foram significativas, mas, a interação entre regularidade-frequência foi significativa $(F(1,39) 17,214, p<.001)$ indicando que as palavras regulares e irregulares de alta frequência são lidas com maior precisão do que as palavras regulares e irregulares de baixa frequência. $O$ efeito de regularidade afeta com maior intensidade a leitura de palavras de baixa frequência indicando que a utilização da via fonológica parece estar restrita à leitura de palavras de BF, por ambos os grupos. É fato que em ortografias transparentes, uma vez que a leitura pela rota fonológica conduz à precisão, a irregularidade tem pouco impacto sobre as palavras muito familiares e o efeito de regularidade passa a ser melhor observado nas palavras de BF. Mesmo neste estudo em que a condição de irregularidade foi especialmente estudada em função da frequência para essa faixa etária, o efeito de regularidade recai sobre as palavras de BF.

Desse modo, a interação entre regularidade, frequência e método indica que o efeito de regularidade afeta de forma diferente os níveis de frequência entre os dois grupos estudados. A regularidade afeta com menor amplitude 0 desempenho em leitura de palavras de AF do grupo de método fônico, do que o do grupo de método global (Figura 2). Com relação às palavras de BF, o efeito de regularidade afeta mais o desempenho do grupo de método fônico do que o do grupo de método global. Nossa hipótese para tal resultado é a de que o grupo de método fônico faz uso de um léxico ortográfico mais extenso e variado, já tendo incorporado um maior número de representações lexicais. Essa hipótese pode também ser confirmada pelo melhor desempenho do grupo de método fônico com relação à leitura de palavras regulares, curtas e longas, de BF e irregulares, curtas, de BF em relação ao do grupo de método global. Observando os desempenhos dos dois grupos podemos afirmar que as palavras de AF, independentemente do nível de regularidade, parecem ser lidas pela rota lexical, por ambos os grupos, apesar de o grupo de método fônico apresentar melhores desempenhos do que o grupo de método global. Já as palavras de BF irregulares, parecem ser lidas pela rota fonológica, por ambos os grupos. 


\section{FIGURA 2}

Interação entre regularidade, frequência e método para leitura de palavras, em termos de precisão
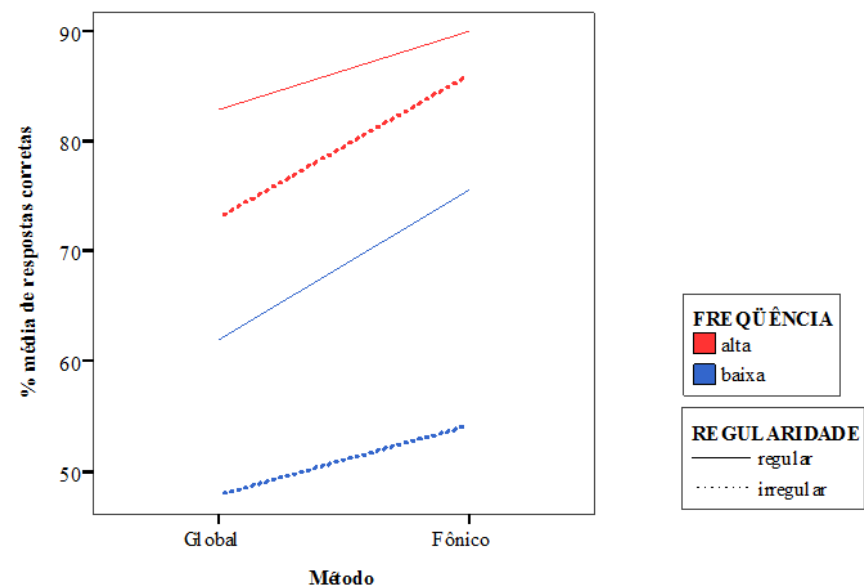

Houve interação entre frequência, extensão e método, em termos de precisão $(F(1,39)=4,729 ; p<$ .05), mas não em termos de velocidade de processamento $(F(1,35)=2,799 ; p>.05)$. Para 0 grupo de método global há uma interferência da extensão do item quando a palavra é de $A F$, indicando um processamento fonológico para os itens longos, em termos de RC apenas (Figura 3). Já para os itens de baixa frequência, a leitura é tão imprecisa que não faz diferença o item ser curto ou longo, indicando também um processamento fonológico. De modo contrário, para o grupo de método fônico há uma interferência da extensão quando o item é de $\mathrm{BF}$, indicando um processamento fonológico. Quando o item é de $\mathrm{AF}$, a extensão não interfere, demonstrando o uso da via lexical para essas palavras. Note-se, ainda, que o desempenho do grupo de método fônico para a leitura dos itens longos de BF é superior ao desempenho em leitura dos itens curtos de BF do grupo de método global. Essas observações indicam que há uma diferença entre os dois grupos com relação à utilização de estratégias lexicais e fonológicas para a leitura de palavras de alta e baixa frequência.

\section{FIGURA 3}

Interação entre frequência, extensão e método para leitura de palavras, em termos precisão.

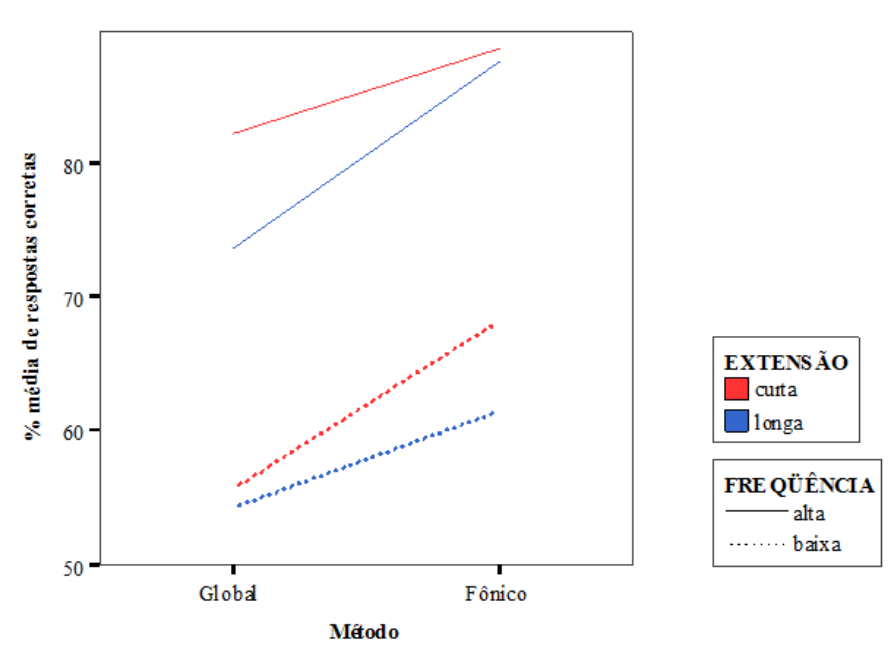

Finalmente, houve interação entre regularidade, frequência, extensão e método, em termos de respostas corretas $(F(1,39)=8,873 ; p<$ .01), mas não em termos de velocidade de processamento $(F<1$.). Esse resultado é produto, primeiramente, da não interferência da extensão sobre os itens regulares e irregulares para ambos os grupos e pela ausência de interação entre extensão e frequência. Houve interação entre regularidade e frequência, mostrando que as palavras de baixa frequência devem estar sendo lidas pela via fonológica. A análise da interação entre regularidade, frequência e método propôs a hipótese de que o grupo de método fônico utiliza mais eficientemente a via lexical, ou possui representações lexicais mais consistentes, do que o grupo de método global. A interação entre frequência $x$ extensão $x$ método também já indicou que o grupo de método global parece utilizar a via fonológica para o processamento tanto dos itens de alta frequência como para os itens de baixa frequência, ao passo que o grupo de método fônico utiliza a via fonológica apenas para o processamento dos itens de baixa frequência e os itens de alta frequência são processados pela via lexical.

Pode-se afirmar, portanto, que as palavras regulares de AF curtas e longas são lidas pela via lexical, por ambos os grupos, apesar de o grupo de método fônico apresentar ligeira vantagem, em termos de precisão. As palavras regulares de BF curtas e longas, apesar de não sofrerem interferência da extensão, o que indicaria o uso da via lexical, são 
lidas com menor precisão do que as palavras regulares de AF. Assim, a interferência da frequência do item, indica que o processo fonológico deve estar sendo utilizado, concomitantemente, para a leitura dessas palavras, em ambos os grupos.

Quando as palavras são irregulares de AF, o grupo de método global lê melhor os itens curtos do que os longos, mostrando uma interferência da extensão. O grupo de método fônico, por sua vez, lê as palavras irregulares de AF curtas e longas praticamente no mesmo nível de precisão, não havendo grande interferência da extensão. Essa constatação parece indicar que o grupo de método fônico possui um léxico ortográfico mais amplo do que o grupo de método global que o possibilita utilizar a rota lexical para a leitura de palavras irregulares de AF. Além disso, o grupo de método fônico lê os itens irregulares de AF longos com o mesmo nível de precisão do que os itens regulares de AF longos, ou seja, a regularidade não interfere, confirmando, assim, o uso da via lexical.

Quando as palavras são irregulares de BF, observa-se que o grupo de método global lê essas palavras, curtas ou longas, com o mesmo nível de precisão. Já o grupo de método fônico lê as palavras irregulares de BF curtas melhor do que as longas. $\mathrm{O}$ desempenho do grupo de método global para as palavras irregulares de BF, ainda que não diferencie entre curtas e longas, é semelhante ao desempenho do grupo de método fônico para as palavras irregulares de BF longas, ou seja, ao pior desempenho do grupo de método fônico. Essa constatação parece indicar que o grupo de método fônico apresenta, com relação às palavras irregulares de BF, um léxico ortográfico mais desenvolvido do que o do grupo de método global.

O conjunto de resultados apresentados indicou a presença, tanto em termos de RC como em termos de RT, dos efeitos de frequência e lexicalidade, por um lado, indicando o uso da via lexical, e a presença dos efeitos de extensão e regularidade, por outro lado, indicando o uso da via fonológica. Não foi constatado efeito método, o que indica que não houve diferenças quanto aos desempenhos observados entre os dois grupos estudados, tanto em RC como em termos de RT, para o processamento da leitura. Tais resultados confirmam que o processamento da leitura no Português brasileiro, mesmo em uma fase inicial, é feito tanto pela rota fonológica, como pela rota lexical, independentemente do método de alfabetização, considerando os grupos estudados.

Apesar de não ter sido constatado efeito principal de método, as análises das interações de terceira e de quarta ordem mostraram diferenças significativas entre os dois métodos (interações significativas para regularidade-frequência-método; frequência-extensão-método e regularidadefrequência-extensão-método), sugerindo que o grupo de método fônico apresenta melhor desenvolvimento das estratégias de processamento de leitura de palavras quando comparadas às do grupo de método global. Com relação à leitura de palavras em comparação à leitura de pseudopalavras, o grupo fônico apresentou indícios do uso da rota lexical para a leitura de palavras de extensão curta (interação entre lexicalidade-extensão-método). Com relação à leitura de palavras, o grupo de método fônico mostrou ligeira vantagem, em termos de $\mathrm{RC}$, nos desempenhos em leitura de palavras regulares de alta e baixa frequência, curtas e longas. Além disso, as análises indicaram que o grupo fônico leu as palavras de AF curtas e longas através da rota lexical. Com relação à leitura de palavras irregulares de AF, o grupo de método fônico claramente também utiliza a rota lexical de maneira mais eficiente do que o grupo de método global. Por outro lado, as palavras irregulares de BF, apesar de terem sido lidas com menor eficiência do que as palavras irregulares de AF, por ambos os grupos, foram lidas com maior eficiência pelo grupo de método fônico. Essa constatação parece indicar um léxico ortográfico mais desenvolvido para o grupo de método fônico.

Esse conjunto de resultados sugere que 0 grupo de método fônico apresenta o processo fonológico e o processo lexical, mais desenvolvidos comparativamente ao grupo de método global. Com relação à velocidade de processamento para leitura de palavras, apenas os efeitos principais de 
lexicalidade, regularidade, frequência e extensão foram significativos, não havendo interações entre os efeitos estudados para ambos os grupos. Esses resultados parecem indicar que a fluência em leitura é uma habilidade adquirida posteriormente. Ao final do $2^{\circ}$ ano, as crianças ainda estão implicadas em alcançar a precisão em leitura.

\section{DISCUSSÃO DOS RESULTADOS}

Os resultados deste estudo indicaram que os dois grupos, de método fônico e global, utilizam a via fonológica e a via lexical para o processamento da leitura já nesta fase inicial de aprendizagem do sistema alfabético. Tal resultado assemelha-se aos resultados obtidos por Pinheiro (1995), reafirmando que a leitura no português brasileiro é processada, mesmo em fases iniciais, por ambas as rotas. A ausência do efeito método indicou que os dois grupos não apresentam diferença quanto aos níveis de desempenho em leitura.

É provável que, como afirma Landerl (2000), em uma ortografia transparente a estrutura ortográfica por si mesma forneça informação clara e suficiente sobre as correspondências grafema-fonema de forma a facilitar o desenvolvimento do processo de decodificação, não havendo interferência do método de ensino. Por outro lado, talvez o contraste oferecido pelos métodos de alfabetização, neste estudo, não tenha sido suficientemente grande.

Outra consideração frente aos resultados é a de que, de certo modo, não se confirma a hipótese de Sprenger-Charoles et al. (2003) de que nas ortografias transparentes haveria maior dependência da rota fonológica do que nas ortografias opacas. Mesmo admitindo-se que o grupo de método fônico possa, a partir da eficiência da rota fonológica, ter desenvolvido melhor a rota lexical, não houve efeito método, indicando que nesta ortografia, para a leitura, mesmo um método de ensino pautado no ensino das correspondências grafema-fonema não resulta em maior dependência da rota fonológica. Por outro lado, poderíamos supor que em função do maior grau de opacidade do processo de escrita para o português brasileiro, a aprendizagem da leitura também estaria influenciada, de forma interativa, pela necessidade de desenvolver a rota lexical concomitantemente.

A análise detalhada das interações quanto às estratégias de processamento da leitura adicionou alguns dados específicos sobre como essas estratégias de leitura se desenvolveram em função do método de ensino. Houve indícios consistentes de que 0 grupo de método fônico apresenta desenvolvimento mais significativo da rota lexical. $O$ grupo de método fônico leu consistentemente as palavras de AF pela rota lexical, ao passo que o grupo de método global parece utilizar simultaneamente a rota fonológica para a leitura dessas mesmas palavras. Além disso, as palavras irregulares de AF foram lidas mais eficientemente pelo grupo de método fônico do que pelo grupo de método global, confirmando o desenvolvimento mais acentuado da rota lexical para este grupo. Quanto à leitura de palavras irregulares de BF, embora ambos os grupos tenham apresentado baixos desempenhos, o grupo de método fônico apresentou desempenho superior em relação ao método global, o que sugere um léxico ortográfico mais desenvolvido para esse grupo.

Tais resultados indicam que o método fônico favoreceu o desenvolvimento da rota lexical, possivelmente em função da estruturação mais consistente da rota fonológica, o que se alinha à visão de Share (1995), de que a rota fonológica é condição sine qua non para aprender a ler nos sistemas alfabéticos. Também estão em conformidade com os achados de Leybaert e Content (1995) quando afirma que o método de ensino, além de não determinar o desenvolvimento prioritário de uma das rotas de processamento, o que imputaria ao grupo de método global o desenvolvimento mais acentuado da rota lexical, não favorece o uso mais eficiente dessa mesma rota quando o método de ensino é global.

Incorporando as afirmativas de Share (1995) e Leybaert e Content (1995), é possível afirmar que o melhor desenvolvimento da rota lexical apresentado pelo grupo de método fônico, neste estudo, teria como alicerce as pistas grafêmicas e morfêmicas 
franqueadas pelo processamento fonológico, e não por representações da palavra como um todo. Nossa hipótese é a de que a eficiência de leitura em uma ortografia transparente possa ser resultante do funcionamento rápido e sofisticado da decodificação fonológica muito mais do que pela ativação das representações ortográficas das palavras.

Uma questão que também se estabelece frente a essas considerações é se tais diferenças, observadas nessa fase inicial de aprendizagem, em função de um método de alfabetização poderão ser significativas ao longo dos anos de escolarização. Conforme postulado pelo efeito Mathew (STANOVICH, 1986), desempenhos insatisfatórios ao início da aprendizagem tendem a aumentar ao longo do processo de aprendizagem. Essa consideração não quer dizer que as crianças expostas ao método global tenham apresentado desempenhos insatisfatórios nessa fase de alfabetização ou que irão apresentar dificuldades com relação ao desenvolvimento posterior da leitura. Parece claro que ambos os grupos desenvolvem-se de maneira satisfatória e paralela. O que se questiona é se a vantagem observada pelo grupo de método fônico, quanto ao uso mais eficiente das rotas fonológica e lexical para a leitura, poderá no futuro, em contato com a demanda de leitura para a aprendizagem de outros conhecimentos e no ambiente letrado, representar diferenças significativas. $\mathrm{Da}$ mesma forma, questiona-se se o método de ensino fônico poderia representar um fator diferencial no caso de crianças com dificuldades de aprendizagem. Evidentemente, apenas 0 prosseguimento da investigação poderá responder a essas questões.

\section{Referências}

ARO, M.; WIMMER, H. Learning to read: English in comparison to six more regular orthographies. Applied Psycholinguistics, 24, p. 621-635, 2003.

COLTHEART, M. et al. DRC: a dual route cascaded model of visual word recognition and reading aloud. Psychol Rev, v. 108, n. 1, p. 204-256, 2001.

DEFIOR, S.; MARTOS, F.; CARY, L. Differences in reading acquisition development in two shallow orthographies: Portuguese and Spanish. Applied Psycholinguistics, 23, p. 135-148, 2002.

GODOY, D. M. A.; PINHEIRO, A. M. V.; DEFIOR, S. C. Processo inicial de alfabetização: influência da consciência fonêmica e método de ensino. Psicologia Teoria e Prática, v. 19, n.3, p. 226-241, 2017.

GOUGH, P. B.; TUNMER, W. E. Decoding, reading, and reading disability. Remedial and Special Education, 7, 1, p. 6-10, 1986.

LANDERL, K. Influences of orthographic consistency and reading instruction on the development of nonword reading skills. European Journal of Psychology of Education, 3, p. 239-257, 2000.

LEYBAERT, J.; CONTENT, A. Reading and spelling acquisition in two different teaching methods: a test of the independence hypothesis. Reading and Writing, 7, p. 65-88, 1995.

LÚCIO, P. S. L.; PINHEIRO, A. M. V. Vinte anos de estudo sobre o reconhecimento de palavras em crianças falantes do português: uma revisão de literatura. Psicologia Reflexão e Crítica, v. 24, 1, 2011. doi: 10.1590/S0102-79722011000100020

PINHEIRO, A. M. V. Reading and spelling development in Brazilian Portuguese. Reading and Writing, 7, p. 111-138, 1995.

Avaliação cognitiva das capacidades de leitura e de escrita de crianças nas séries iniciais do Ensino Fundamental - AVACLE: relatório final global e integrado de atividades desenvolvidas. Submetido ao CNPq, 2003

SALLES, J. F.; PARENTE, M. A. M. Avaliação da leitura e escrita de palavras em crianças de $2^{\mathrm{a}}$ série: Abordagem neuropsicológica cognitiva. Psicologia: Reflexão e Crítica, 20(2), 220-228, 2007.

SALLES, J. F.; PARENTE, M. A. M. P. Relação entre os processos cognitivos envolvidos na leitura de palavras e as habilidades de consciência fonológica em escolares. Pró-fono Revista de Atualização Científica, Carapicuiba (SP), v. 14, n.2, p.175-186, 2002.

SHARE, D. L. Phonological recoding and selfteaching: sine qua non of reading acquisition. Cognition, 55, p. 151-218, 1995.

SPRENGER-CHAROLLES, L.; SIEGEL, L. S.; BÉCHENNEC, D.; SERNICLAES, W. Development of phonological and orthographic processing in reading aloud, in silent reading, and in spelling: A four-year longitudinal study. Journal of Experimental Child Psychology, 84, p.194-217, 2003.

STANOVICH, K. E. Matthew effects in reading: some consequences of individual differences in the 
acquisition of literacy. Reading Research Quartely, 21, p.360-407, 1986.

SUCENA, A.; CASTRO, S. L. Estratégias fonológicas e ortográficas na aprendizagem da leitura do português europeu. Iberpsicologia 10, 3, 2005. Disponível em: https://repositorioaberto.up.pt/bitstream/10216/5430/2/83694.pdf

WIMMER, H.; GOSWAMI, U. The influence of orthographic on reading development: word recognition in English and German children. Cognition, 51, p. 91-103, 1994.

ZOCCOLOTTI, P.; LUCA, M. De; FILIPPO, G. Di; JUDICA, A.; MARTELLI, M. Reading development in an orthographically regular language: effects of length, frequency, lexicality and global processing ability. Reading and Writing, 22, p. 1053-1079, 2009. doi: 10.1007/s11145-008-9144-8

\section{COMO CITAR ESSE ARTIGO}

ALVES GODOY, Dalva Maria; PINHEIRO, Ângela Maria Vieira. Desenvolvimento das estratégias de leitura em dois diferentes métodos de alfabetização. Signo, Santa Cruz do Sul, v. 43, n. 77, jul. 2018. ISSN $1982-2014$. Disponível em: <https://online.unisc.br/seer/index.php/signo/article/view/12070>. Acesso em: doi: http://dx.doi.org/10.17058/signo.v43i77.12070. 